\title{
Crioglobulinemia: RelaçÃo entre hepatite C E GLOMERULONEFRITE
}

\author{
CRYOGLOBULINEMIA: LINK BETWEEN HEPATITIS C AND \\ GLOMERULONEPHRITIS
}

Clin Biomed Res. 2018;38(2):196-199

1 Programa de Residência Médica em Clínica Médica, Hospital Santa Cruz. Santa Cruz do Sul, RS, Brasil.

2 Departamento de Biologia e Farmácia, Universidade de Santa Cruz do Sul (UNISC). Santa Cruz do Sul, RS, Brasil.

Autor correspondente: Alice de Moraes Baier alice.moraesbaier@hotmail.com Hospital Santa Cruz Rua Fernando Abott, 174. 96810-150, Santa Cruz do Sul, RS, Brasil. Juliana Lopes Peixoto ${ }^{1}$, Marjana Denti Piana ${ }^{2}$, Alice de Moraes Baier ${ }^{2}$,
Leandro Bizarro Muller ${ }^{1,2}$, Marcelo Carneiro ${ }^{1,2}$, Claus Dieter Dummer $^{1,2}$

\section{RESUMO}

A Hepatite C é um problema de saúde mundial. Uma associação entre infecção pelo vírus da hepatite $\mathrm{C}(\mathrm{HCV})$ e crioglobulinemia mista com doença renal tem sido descrita, sendo a glomerulonefrite membranopoliferativa (GNMP) tipo I o acometimento renal mais comum. A GNMP é frequentemente associada com a crioglobulinemia mista tipo II. Esse relato de caso objetiva descrever fatores clínicos dos pacientes com crioglobulinemia mista, a qual é uma manifestação extra-hepática da infecção por $\mathrm{HCV}$, assim como discutir a sua fisiopatologia e tratamento, baseado no relato de caso.

Palavras-chave: Crioglobulinemia; hepatite C; hepatite C crônica, glomerulonefrite; glomerulonefrite membranoproliferativa

\section{ABSTRACT}

Hepatitis $C$ is a public health concern worldwide. An association of hepatitis $C$ virus $(\mathrm{HCV})$ infection with mixed cryoglobulinemia and renal disease has been described, and type I membranoproliferative glomerulonephritis (MPGN) is the most common. MPGN is often associated with type II mixed cryoglobulinemia. This case report aimed to describe the clinical features of patients with mixed cryoglobulinemia, a major extrahepatic manifestation of HCV infection, and to discuss its pathophysiology and treatment of $\mathrm{HCV}$ infection based on the case report.

Keywords: Cryoglobulinemia; hepatitis C; chronic hepatitis C; glomerulonephritis; glomerulonephritis membranoproliferative

A Hepatite C é uma doença contagiosa causada por um vírus RNA do gênero Hepacivirus e família Flaviviridae, que afeta mais de 150-170 milhões de pessoas no mundo ${ }^{1}$. É uma doença sistêmica que muitas vezes pode estar associada a manifestações extra-hepáticas ${ }^{2}$, entre elas, a crioglobulinemia associada a glomerulopatias. Vários tipos histológicos de doenças renais são relatados em associação com a infecção pelo HCV, incluindo glomerulonefrite membranoproliferativa (GNMP), nefropatia membranosa, glomeruloesclerose segmentar e focal, nefropatia por IgA, microangiopatia trombótica e nefrite intersticial ${ }^{3}$. Clinicamente, manifestações renais em pacientes infectados pelo HCV incluem proteinúria, hematúria, hipertensão, nefrite aguda e síndroma nefrótica ${ }^{4}$.

\section{CASO}

Paciente do sexo masculino, branco, 51 anos, admitido no Hospital Santa Cruz no dia 21/11/2012 para a investigação de púrpura palpável distribuída nos membros inferiores e no abdômen. Apresentava história de cardiopatia congênita corrigida cirurgicamente há 40 anos. Iniciou com episódios de púrpura palpável nos membros inferiores, que apresentavam periodicidade de três meses, com melhora espontânea após alguns dias do início do quadro, 
há doze anos (Figura 1). Tais lesões sempre foram tratadas como dermatite alérgica. Tinha artralgia, especialmente nas mãos e nos joelhos. Nos últimos seis meses, iniciou com cefaleia do tipo enxaqueca, dor epigástrica, crises de dispneia e hipertensão arterial sistêmica, o que motivou diversas consultas no setor de emergência do hospital.

Em agosto de 2012, associado ao quadro de púrpura, iniciou com edema em membros inferiores. Consultou no ambulatório de Cardiologia por suspeita de insuficiência cardíaca. Não confirmando o diagnóstico, foi encaminhado para o ambulatório de Nefrologia, devido à perda de função renal (creatinina $1,69 \mathrm{mg} / \mathrm{dl}$ e uréia $108 \mathrm{mg} / \mathrm{dl}$ ), sendo confirmado proteinúria nefrótica (3.500 mg/24 horas). Ao exame físico, apresentava-se em bom estado geral, descorado e com pressão arterial de 150/100 mmHg. Ausculta cardíaca com sopro sistólico de foco aórtico $(2+/ 4+)$ e ausculta respiratória normal. Abdômen flácido e indolor a palpação, sem visceromegalias. Ao exame de pele, verificou-se exantema máculo-papular eritematoso em região de abdomen, dorso e membros inferiores, predominantemente. Edema 2+/4 nos membros inferiores.

Demais exames laboratoriais mostravam leucócitos 4.400 (bastões $1 \%$ e segmentados $89 \%$ ), hematócrito $32,5 \%$, hemoglobina $10,7 \mathrm{mg} \%$, plaquetas 123.000 , VSG $43 \mathrm{~mm}$, potássio $6,5 \mathrm{mg} / \mathrm{dl}$ e sódio $143 \mathrm{mg} / \mathrm{dl}$. Ainda, T4 livre 0,770 ng/dl, TSH 5,26 ulU/ml, TP 11,7 s" (INR 1,00), glicose $86 \mathrm{mg} / \mathrm{dl}$, ácido úrico $8,4 \mathrm{mg} / \mathrm{dl}$, bilirrubina total 0,58 mg/dl (bilirrubina direta $0,16 \mathrm{mg} / \mathrm{dl}$ ), proteínas totais $5,8 \mathrm{~g} / \mathrm{dl}$ albumina $3,1 \mathrm{~g} / \mathrm{dl}$ e globulinas $2,7 \mathrm{~g} / \mathrm{dl}$. A pesquisa de anticorpo anti-MBG $\lg \mathrm{g}$ foi positiva com título 1:80, e o ANCA P e ANCA C foram negativos. Sorologias para HIV e Hepatite B foram não reagentes e sorologia para hepatite $C$ foi reagente. Diagnosticado hepatite $\mathrm{C}$ com genótipo 3 e carga viral de $24.338 \mathrm{UI} / \mathrm{ml}$. A pesquisa de crioglobulinas foi positiva. Foi realizada biópsia renal em 22/11/2012, tendo como resultado no anatomopatológico glomerulonefrite membranoproliferativa tipo I, com dano tubular agudo de leve a moderado, ausência de sinais relevantes de cronicidade e aterosclerose discreta (Figura 2). A imunoflourescência evidenciou depósito difuso, de padrão granular e predominantemente no mesângio, de lgG e lgM (moderado), C3 (discreto) e C1q (tênue).

Após a confirmação diagnóstica em dezembro de 2012, a terapia foi iniciada com Interferon Peguilado alfa $2 \mathrm{a}, 180 \mathrm{mcg}$ SC por semana e Ribavirina $1.000 \mathrm{mg}$ por dia. Foram necessários ajustes na dose da Ribavirina (reduzida para $500 \mathrm{mg} / \mathrm{dia}$ ) devido à anemia e à insuficiência renal. A pesquisa de RNA do vírus $C$ foi negativa na quarta semana de tratamento, confirmando a resposta viral rápida aos

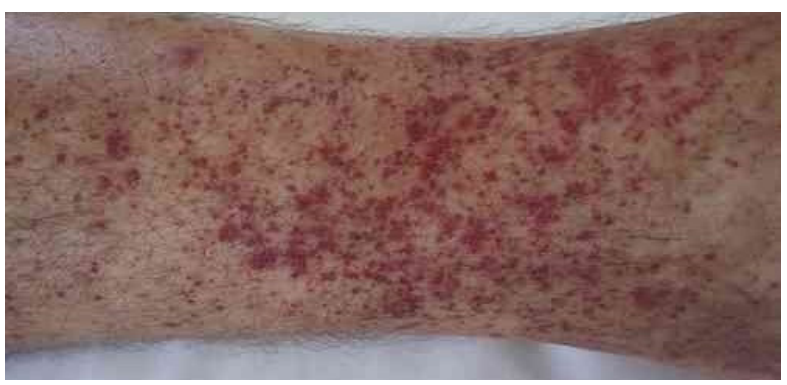

Figura 1: Púrpura palpável em membro inferior direito.

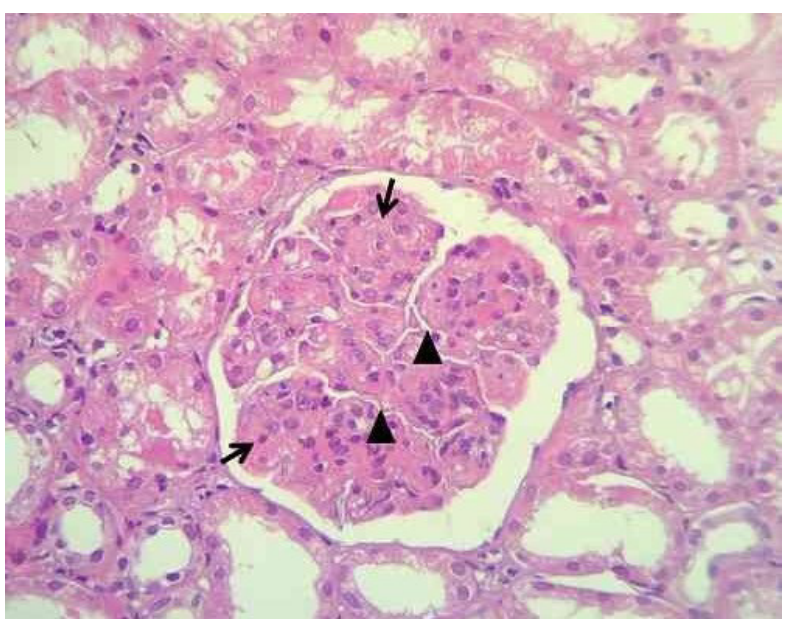

Figura 2: Biópsia renal mostrando um glomérulo com aparência lobular devido à proliferação endocapilar difusa (seta) e espessamento multifocal da membrana basal (cabeça da seta) (HE, 400x).

anti-virais, sendo este mantido até junho de 2013. Em janeiro de 2013 e maio de 2014, a pesquisa de crioglobulinas e a quantificação viral foram negativas. Paciente permaneceu estável, com recuperação da função renal, tendo alta ambulatorial em 2015.

\section{DISCUSSÃO}

A crioglobulinemia é uma síndrome inflamatória sistêmica que envolve uma vasculite de pequenos e médios vasos, na qual são detectados imunocomplexos contendo crioglobulinas ${ }^{5-6}$. O mecanismo de lesão vascular é tipicamente atribuído ao C1q, componente ativo do complemento incorporado ao complexo da crioglobulina. Assim, a lesão endotelial ocorre pela ativação da cascata do complemento através da via clássica, bem como pela ligação a receptores do complemento no endotélio ${ }^{7}$. A ativação do complemento gera fatores quimiotáticos como C3a e C5a, que recrutam e ativam leucócitos pró-inflamatórios. Isso também leva à formação de C5-9 e por fim do complexo de 
ataque a membrana, que tem um papel importante no dano endotelial ${ }^{7}$. Também deve-se considerar o efeito direto do vírus sobre as células endoteliais ${ }^{5}$, uma vez que o antígeno do HCV foi identificado nos glomérulos sem anticorpos detectáveis por ensaios como ELISA, ou mesmo por replicação viral no sangue periférico através da reação em cadeia da polimerase. Isso pode explicar a aterosclerose acelerada nos pacientes HCV positivos, bem como a progressão relativamente rápida para doença renal crônica².

A lesão na vasculite caracteriza-se por injúria endotelial, necrose de pequenos vasos, inflamação perivascular com presença de linfócitos e infiltração neutrofílica, oclusão luminal por crioglobulinas e trombos de fibrina. Nos rins, isso leva à necrose fibrinóide focal do tufo glomerular, com formação de crescentes ${ }^{7}$.

As crioglobulinas são classificadas com base na imuno-histoquímica em tipos I, II e III, particularmente considerando a atividade de ligação do fator reumatóide. No tipo I, uma única imunoglobulina monoclonal é crioprecipitada, enquanto que nos tipos II e III existe uma crioglobulinemia mista essencial (CME), composta por pelo menos duas imunoglobulinas, monoclonal e policlonal ${ }^{5,6}$.

A infecção por HCV chega a representar a causa da crioglobulinemia em $80 \%$ dos $\operatorname{casos}^{5}$. As manifestações clínicas mais comuns da crioglobulinemia associada ao HCV incluem sintomas cutâneos como máculas eritematosas, púrpura palpável, crostas hemorrágicas, úlceras, fenômeno de Raynaud, livedo reticular e hiperpigmentação pós-inflamatória ${ }^{5-8}$. Manifestações neurológicas também podem estar presentes. A neuropatia periférica manifesta-se por dor intensa e parestesia assimétrica, evoluindo para déficit motor. Entretanto, muitos pacientes são assintomáticos e, frequentemente, só apresentam púrpura palpável transitória ${ }^{8}$.

Os pacientes com envolvimento renal normalmente apresentam maior prevalência da crioglobulinemia mista, sendo descrita como glomerulonefrite crioglobulinêmica. A glomerulonefrite membranoproliferativa é o padrão histológico mais encontrado ${ }^{4}$. Além da GNMP, outras formas de doença glomerular têm sido associadas com a infecção pelo HCV, como nefropatia por lgA, glomerulonefrite pós-infecciosa, nefropatia membranosa, microangiopatias trombóticas e glomerulosclerose segmentar e focal. As crioglobulinas precipitam no mesângio, devida à afinidade do fator reumatóide Kappa IgM (j-RF) pela fibronectina celular que está presente na matriz mesangial ${ }^{3}$, iniciando ali o processo inflamatório. O complemento também ativa o endotélio glomerular através da adesão das crioglobulinas circulantes que se depositam nos capilares glomerulares. Na GNMP há proliferação endocapilar e depósitos subendoteliais e/ou intraluminais de crioglobulinas, imunoglobulinas e proteínas do complemento. Menos comumente, podem ocorrer trombos hialinos intraglomerulares e vasculite com necrose fibrinoide. Na microscopia eletrônica, depósitos sudendoteliais granulares densos e amorfos podem estar presentes ${ }^{4}$.

Quanto às manifestações clínicas da doença renal, pode-se incluir hematúria, cilindros hemáticos, proteinúria nefrótica e insuficiência renal ${ }^{1-4}$. Mais da metade dos pacientes têm somente proteinúria e/ou hematúria ${ }^{4}$. A doença glomerular pode manifestar-se como insuficiência renal aguda oligúrica em 5 a 10\% dos casos. A síndrome nefrítica é diagnosticada em aproximadamente $20 \%$ dos casos. A hipertensão arterial é comum, pode ser grave e de difícil controle, afetando 50 a $80 \%$ dos pacientes no momento do diagnóstico ${ }^{4}$. A gravidade da hipertensão arterial pode refletir a gravidade da doença renal ${ }^{4}$. O curso clínico dos pacientes com CME é variável. Alguns pacientes têm um curso indolente, e a insuficiência renal com necessidade de diálise é rara ( $10 \%$ dos casos $)^{9}$.

Até então, o tratamento era realizado com Interferon Alfa Peguilado, associado a Ribavirina, ambos escolhidos para tratamento da infecção crônica da Hepatite C, que resultaram em um maior número de respostas virológicas sustentadas' e sintomas clínicos em até $88 \%$ dos pacientes ${ }^{10}$. Recentemente, foram introduzidos novos tratamento, como Sofosbuvir, Daclatasvir e Simeprevir. O Sofosbuvir é um análogo nucleotídeo que inibe a polimerase do HCV; o Simeprevir é um inibidor de protease de segunda geração; e o Daclatasvir é um inibidor da NS5A. Essas medicações atuam diretamente no HCV, interrompendo a sua replicação, e constituem avanços recentes no tratamento da hepatite crônica pelo vírus $\mathrm{C}$. Os novos tratamentos, conforme o genótipo, chegam a atingir $90-100 \%$ de resposta virológica sustentada ${ }^{11}$.

Estuda-se ainda o antígeno CD20, uma proteína transmembrana que é expressa seletivamente em linfócitos pré-B e linfócitos maduros, em que as células CD20-positivas são expandidas e ativadas em pacientes com crioglobulinemia. Por esse motivo, propôs-se usar Rituximab, um anticorpo monoclonal que atua especificamente contra o antígeno CD20, para o tratamento de pacientes com $\mathrm{HCV}$ relacionado à crioglobulinemia refratários a terapia antiviral convencional, ou que apresentaram recaída da doença após a terapia ${ }^{11}$. Como o paciente respondeu a terapia inicial, não foi necessária uma intervenção adicional.

Dessa forma, como uma regra geral, a escolha do tratamento mais adequado para um determinado paciente é baseada pelo nível de atividade da doença, pela extensão e pela gravidade dos sintomas ${ }^{9}$. O estudo foi realizado no: Hospital Santa Cruz, Santa Cruz do Sul, RS, Brasil.

\section{Conflitos de Interesse}

Os autores declaram não ter conflito de interesse. 


\section{REFERÊNCIAS}

1. Cacoub P, Gragnani L, Comarmond C, Zignego AL. Extrahepatic manifestations of chronic hepatitis $\mathrm{C}$ virus infection. Dig Liver Dis. 2014;46(Suppl 5):S165-73. http:// dx.doi.org/10.1016/j.dld.2014.10.005. PMid:25458776.

2. Latt N, Alachkar N, Gurakar A. Hepatitis $C$ virus and its renal manifestations: a review and update. Gastroenterol Hepatol. 2012;8(7):43445. PMid:23293553.

3. Ozkok A, Yildiz A. Hepatitis c virus associated glomerulopathies. World J Gastroenterol. 2014;20(24):754454. http://dx.doi.org/10.3748/wjg.v20. i24.7544. PMid:24976695.

4. Fabrizi F, Plaisier E, Saadoun D, Martin P, Messa P, Cacoub P. Virus Infection, mixed cryoglobulinemia, and kidney disease. Am J Kidney Dis. 2013;61(4):623-37. http://dx.doi. org/10.1053/j.ajkd.2012.08.040. PMid:23102733.
5. Ramos-Casals M, Stone JH, Cid MC, Bosch X. The cryoglobulinaemias. Lancet. 2012;379(9813):348-60. http://dx.doi.org/10.1016/S01406736(11)60242-0. PMid:21868085.

6. Cacoub P, Comarmond C, Domont F, Savey L, Saadoun D. Cryoglobulinemia vasculitis. Am J Med. 2015;128(9):950. PMid:25837517.

7. Barsoum RS, William EA, Khalil SS. Hepatitis $C$ and kidney disease: a narrative review. J Adv Res. 2017;8(2):113-30. http://dx.doi. org/10.1016/j.jare.2016.07.004. PMid:28149647.

8. Lauletta G, Russi S, Conteduca V, Sansonno L. Hepatitis C virus infection and mixed cryoglobulinemia. Clin Dev Immunol. 2012,2012:11. http://dx.doi.org/10.1155/2012/502156
9. Dammacco F, Sansonno D.

Therapy for Hepatitis $C$ vírus-related cryoglobulinemic vasculitis. N Engl J Med. 2013;369(11):1035-45. http:// dx.doi.org/10.1056/NEJMra1208642. PMid:24024840.

10. Visentini M, Tinelli C, Colantuono S, Monti M, Ludovisi S, Gragnani L, et al. Efficacy of low-dose rituximab for the treatment of mixed cryoglobulinemia vasculitis: phase II clinical trial and systematic review. Autoimmun Rev. 2015;14(10):889-96. http://dx.doi. org/10.1016/j.autrev.2015.05.013. PMid:26031898.

11. Brasil. Ministério da Saúde. Secretaria de Vigilância em Saúde. Departamento de DST, Aids e Hepatites Virais. Protocolo clínico e diretrizes terapêuticas para Hepatite $C$ e coinfecções. Brasília: Ministério da Saúde; 2015. 